\title{
Homozygous loss of a cysteine residue in the glucocerebrosidase gene results in Gaucher's disease with a hydropic phenotype
}

\author{
Heather J Church ${ }^{*}{ }^{1}$, Alan Cooper ${ }^{1}$, Fiona Stewart ${ }^{2}$, Claire M Thornton ${ }^{3}$ and \\ J Edmund Wraith ${ }^{1}$
}

\author{
${ }^{1}$ Willink Unit, Royal Manchester Children's Hospital, Pendlebury, Manchester M27 4HA, UK; ${ }^{2}$ Northern Ireland \\ Regional Genetics Service, Belfast City Hospital, Lisburn Road, Belfast BT9 7AB, UK; ${ }^{3}$ Northern Ireland Regional \\ Perinatal Pathology Service, Royal Group of Hospitals Trust, Belfast BT12 6BA, UK
}

Acute neuronopathic Gaucher's disease is classically considered to be a disease of late infancy, but also includes a spectrum of variant phenotypes such as perinatal lethal hydrops, or the collodian baby phenotype in the newborn period. These extreme phenotypes are frequently associated with recombinant alleles, nonsense mutations and rare missense mutations. In this report, we present a family with multiple incidence of a hydrops where Gaucher's disease was confirmed. Mutational analysis revealed the homozygosity for the missense mutation C16S, which is located in exon 3 and results in the loss of a cysteine residue. This genotype would be predicted to result in virtually zero enzyme activity. European Journal of Human Genetics (2004) 12, 975-978. doi:10.1038/sj.ejhg.5201251

Published online 4 August 2004

Keywords: Gaucher's disease; lysosomal storage disorder; hydrops fetalis; mutation analysis

\section{Introduction}

Gaucher's disease is the most common known lysosomal sphingolipid storage disorder. It is due to reduced or deficient lysosomal glucocerebrosidase ( $\beta$-glucosidase) activity, which leads to storage of glucocerebroside within lysosomes. ${ }^{1}$ The clinical presentation of the disorder is extremely heterogeneous and for convenience is divided into three subtypes. Type I or non-neuronopathic Gaucher's disease occurs at the highest frequency among the Ashkenazi Jewish community. It is characterised by hepatosplenomegaly, haematological abnormalities and bone disease, but central nervous system involvement is absent. ${ }^{2}$ Type III or subacute neuronopathic Gaucher's disease has a variable spectrum of

*Correspondence: Dr HJ Church, Willink Unit, Royal Manchester Children's Hospital, Pendlebury, Manchester M27 4HA, UK. Tel: +44 161727 2307; Fax: + 44161727 2303; E-mail: Heather.Church@cmmc.nhs.uk Received 23 March 2004; revised 21 May 2004; accepted 25 May 2004 symptoms but neurological deterioration is less rapid than in acute Type II disease. ${ }^{3}$ Type II or acute neuronopathic Gaucher's disease presents with earlyonset severe neurological deterioration and gross organomegaly. Death usually occurs before 2 years of age. A subgroup of Type II, the perinatal lethal form, is associated with ichthyosis, the collodion baby syndrome, neonatal death or hydrops fetalis and death in utero. ${ }^{4-7}$ It is thought that this subgroup is associated with a complete lack of functional enzyme, often the result of a combination of null alleles at the molecular level. ${ }^{6-8}$ We report a family with three fetuses affected by the most severe form of Type II disease presenting with hydrops fetalis and intrauterine death. The underlying genetic lesion was a homozygous loss of the second cysteine residue in the glucocerebrosidase protein (C16S). This appears to have a severe effect on the tertiary structure of the enzyme protein resulting in the absence of any functional enzyme. 


\section{Materials and methods}

Pathology specimens were obtained at postmortem examination of the second hydropic fetus. Genomic DNA was isolated for the proband from cultured amniocytes and for the parents from peripheral blood leucocytes by standard laboratory procedures. The entire coding region of the glucocerebrosidase gene was amplified by PCR using primers and conditions shown in Table 1 or previously described. ${ }^{9}$ Each exon was sequenced using an ABI prism 377 sequencer and the dRhodamine sequencing kit (Applied Biosystems, Warrington, UK) according to the manufacturer's instructions as previously described. ${ }^{9}$

\section{Case report}

$\mathrm{Mr}$ and Mrs R are full first cousins with their mothers being sisters, and are of Pakistani origin. The family pedigree is shown in Figure 1. There was no family history of note and in particular there was no history of intrauterine or neonatal death. Their first pregnancy resulted in the birth of a healthy daughter who is now aged 8 years. In the second pregnancy, there was an intrauterine death at 26 weeks gestation. The baby was noted to have a birth weight of $1670 \mathrm{~g}$, which at 26 weeks is strongly suggestive of the presence of fetal hydrops. We have no other details of this pregnancy. In the third pregnancy, there was a spontaneous abortion at 8 weeks. The fourth pregnancy initially appeared to be progressing normally, although the mother did comment that she felt fetal movement was somewhat reduced. An ultrasound scan at 30 weeks showed the presence of fetal hydrops and fetal bradycardia. An emergency caesarean section was performed and a markedly hydropic baby girl was delivered. Unfortunately, she could not be resuscitated and subsequently died. Blood was taken at birth for virology and viral titres were negative. Chromosome analysis showed the baby to have a normal
46,XX karyotype and haemoglobin electrophoresis excluded thalassaemias known to be associated with hydrops. A post mortem carried out on this baby showed her to be a fresh stillbirth with a weight of $1768 \mathrm{~g}$. There was marked fetal hydrops with a pericardial effusion, a small amount of ascites, marked hepatosplenomegaly and an enlarged, dilated, flabby heart weighing $13.8 \mathrm{~g}$ (expected weight $7 \pm 2.8 \mathrm{~g}$ ). The placenta was massively enlarged weighing $640 \mathrm{~g}$. It was also noted to be oedematous and friable.

Histological examination of the thymus showed massive replacement of the thymic medulla and cortex by large cells with abundant pale eosinophilic cytoplasm and peripheral nuclei (Figure 2). The cytoplasm had a rather

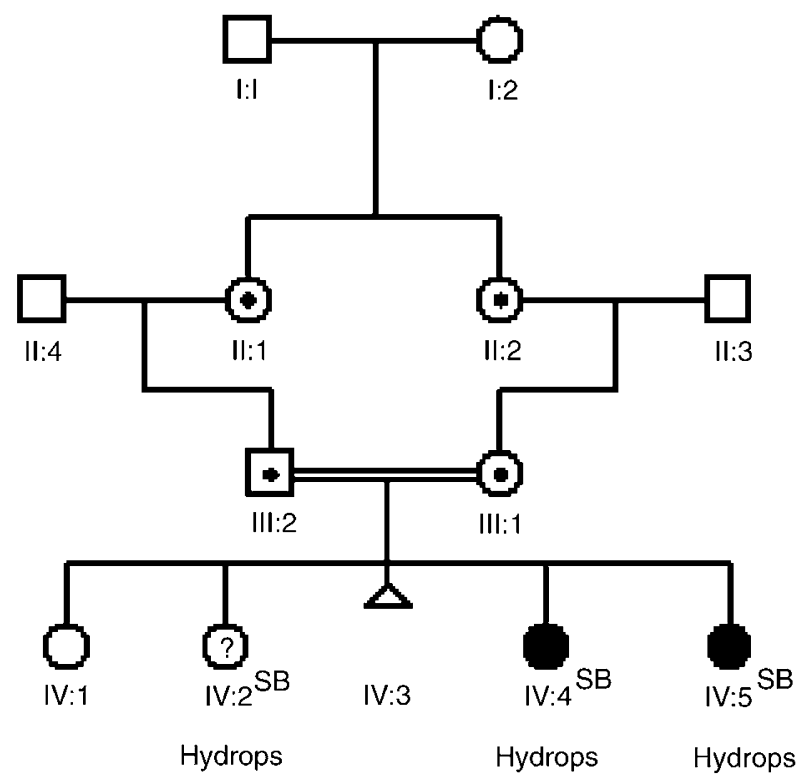

Figure 1 Family pedigree.

Table 1 Primers for PCR and sequencing of the glucocerebrosidase gene

\begin{tabular}{|c|c|c|c|c|}
\hline Exon & Genomic no. & Primer sequence & Annealing temp. $\left({ }^{\circ} \mathrm{C}\right)$ & Product (bp) \\
\hline 2 & $\begin{array}{l}1792 \\
2213\end{array}$ & 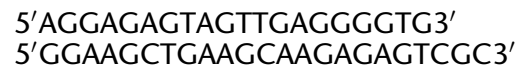 & 58 & 421 \\
\hline 3 & $\begin{array}{l}2434 \\
2750\end{array}$ & $\begin{array}{l}\text { 5'ATGTGTCCATTCTCCATGTCTTCA3' } \\
\text { 5'CACTGACACCATTTACСTCTA3' }^{\prime}\end{array}$ & 58 & 315 \\
\hline 4 & $\begin{array}{l}2615 \\
3003\end{array}$ & $\begin{array}{l}\text { 5'TGAGAGTACACGCAGTGGGCGAC } 3^{\prime} \\
5^{\prime} G G A A G C T G A A G C A A G A G A G T C G C 3^{\prime}\end{array}$ & 58 & 388 \\
\hline $5-6$ & $\begin{array}{l}3623 \\
4690\end{array}$ & $\begin{array}{l}5^{\prime} \text { CTGACACTTTICTTGCCCT3' } \\
5^{\prime} \text { GTGACAGAGAGAGAGACTCC } 3^{\prime}\end{array}$ & 58 & 1067 \\
\hline 5 & $\begin{array}{l}3860 \\
4120\end{array}$ & $\begin{array}{l}5^{\prime} \text { GCAGAGTCCCATACTCTCCT3' } \\
\text { 5'TACCCTACAGGTTCTCAACC } 3^{\prime}\end{array}$ & 61 & 260 \\
\hline 6 & $\begin{array}{l}4219 \\
4483\end{array}$ & $\begin{array}{l}\text { 5'GTGTTCCAACTCTGGGTGCT3' } \\
\text { 5'TAAATGGGAGGCGAGTCCTG } 3^{\prime}\end{array}$ & 61 & 264 \\
\hline 7 & $\begin{array}{l}4845 \\
5312\end{array}$ & $\begin{array}{l}\text { 5'TTCGCCAGGCTGTTCTCGAAC3' } \\
\text { 5'GAAATCGCTCTAAGTTTGGGAGC3' }\end{array}$ & 58 & 467 \\
\hline 8 & $\begin{array}{l}5999 \\
6415\end{array}$ & $\begin{array}{l}\text { 5'GTTGCATTCTTCCCGTCACC } 3^{\prime} \\
\text { 5'CTGGACAGGAAGGGCTTCTG3' }\end{array}$ & 61 & 416 \\
\hline
\end{tabular}




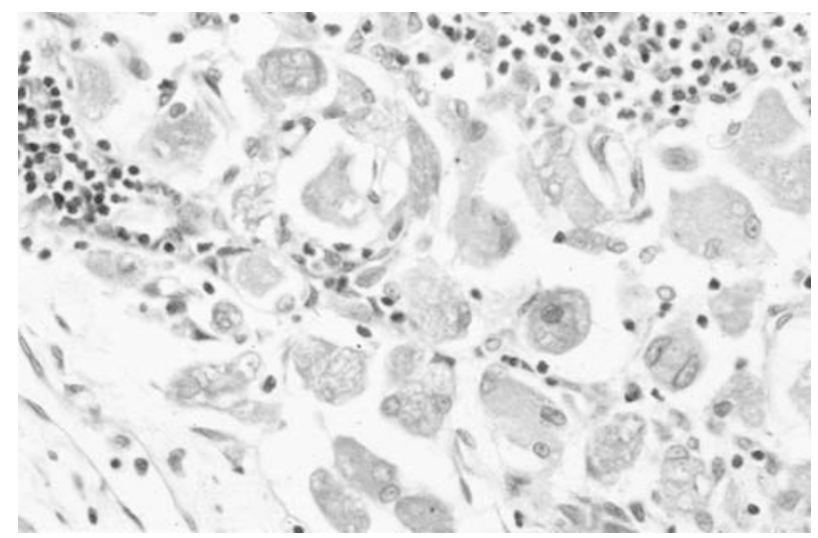

Figure 2 PAS-stained section of thymus showing abundant Gaucher cells.

granular appearance and the appearances were compatible with the presence of Gaucher cells. Histology of the spleen showed congestion and sheets of Gaucher cells, which virtually obliterated the underlying normal structure. Gaucher cell infiltration was also found within the heart muscle, the lungs and liver. The bone marrow also showed extensive replacement by sheets of Gaucher cells. A fibroblast culture was set up from skin and a deficiency of glucocerebrosidase ( $\beta$-glucosidase) was found confirming the diagnosis of Gaucher's disease.

In the fifth pregnancy, an amniocentesis was carried out at 13 weeks gestation. This showed a marked deficiency of $\beta$-glucosidase activity with a level of $2 \mathrm{nmol} / \mathrm{mg} / \mathrm{h}$ (control 55 , residual activity $3.6 \%$ of control activity), suggesting the fetus to be affected by Gaucher's disease. Further DNA analysis of the amniocytes showed the baby to be homozygous for the point mutation C16S, which occurs in exon 3 of the glucocerebrosidase gene and results in a cysteine being substituted by a serine. No other sequence changes were detected. Subsequent DNA analysis showed both the parents to be heterozygous for the point mutation C16S. The grandmothers are also assumed to be carriers, but this has not been shown.

Although the parents knew that the outlook for this baby was extremely poor, they elected to continue with the pregnancy. The pregnancy was monitored by ultrasound scan. At 33 weeks gestation, the mother reported feeling little fetal movement for the previous 3 days and an ultrasound scan showed that there had been an intrauterine death. Labour was induced and she delivered a stillborn female infant weighing $2.9 \mathrm{~kg}$. No postmortem examination was performed.

In summary, this couple who are both carriers of the C16S mutation have had five pregnancies in total resulting in one healthy living daughter. In addition, they have had one early miscarriage and three stillborn infants with severe hydrops fetalis.

\section{Discussion}

This case report has identified a genotype of homozygous C16S in a perinatal lethal case of Gaucher's disease. This extreme manifestation of Gaucher's disease may be expected to be associated with zero enzyme activity. Previous reported cases of hydrops in Gaucher's disease have shown a prevalence of homozygosity for recombinant alleles and null mutations where the genotype would be expected to result in zero enzyme activity. 6,7 The case presented in this study has shown a null phenotype as a result of homozygosity for a missense mutation, an observation that has been previously reported once where homozygosity for the missense mutation H311R also resulted in a hydrops phenotype. ${ }^{4,6}$ These cases demonstrate that missense mutations can give rise to null phenotypes.

The loss of a cysteine has previously been observed in the missense mutation $\mathrm{C} 342 \mathrm{G}$, which resulted in a Type II phenotype in combination with G325R. ${ }^{10}$ We have previously reported C16S in combination with $\mathrm{D} 409 \mathrm{H}$, which resulted in a severe Type II/III phenotype. ${ }^{11}$ The missense mutation C16S (TGT > TCT) converts the second cysteine in exon 3 to a serine residue. It would be predicted to disrupt the first disulphide bond within domain 1 of the X-ray structure of the glucocerebrosidase molecule, ${ }^{12}$ thought to be required for correct protein folding. This would be predicted to destroy enzyme activity. The case presented in this study has demonstrated that C16S in its homozygous state results in the most severe hydrops presentation of Gaucher's disease. Our previous report suggested that $\mathrm{C} 16 \mathrm{~S}$ is a severe mutation, as in combination with $\mathrm{D} 409 \mathrm{H}$ usually associated with Type III disease it resulted in a more severe Type II/III phenotype. ${ }^{11}$ These in vivo observations are consistent with site-directed mutagenesis, which has shown that all cysteines except for C126 are necessary for enzyme activity. ${ }^{13}$

It has been suggested that the true incidence of perinatal lethal Gaucher's disease may be underestimated due to misclassification as hydrops of unknown cause. ${ }^{4}$ A recent review of perinatal Gaucher's disease supports this suggestion, finding $56 \%$ of cases studied presented with nonimmune hydrops fetalis. ${ }^{7}$ This case study is further demonstration of the importance of considering Gaucher's disease in the differential diagnosis of fetal hydrops. The C16S mutation has to date been reported in families of Pakistani origin and it may be that this mutation has arisen in the Asian population.

\section{References}

1 Beutler E, Grabowski GA: Gaucher disease; in Scriver CR, Beaudet $\mathrm{AL}$, Sly WS, Valle D (eds): The Metabolic and Molecular Bases of Inherited Disease 2001, 8th edn, vol 3: pp 3635-3668.

2 Cox TM, Schofield JP: Gaucher's disease: clinical features and natural history; in Zimran A (ed): Balliere's Clinical Haematology: Gaucher's Disease 1997, vol 10:4: pp 657-689. 
3 Erikson A, Bembi B, Schiffmann R: Neuronopathic forms of Gaucher's disease; in Zimran A (ed): Balliere's Clinical Haematology: Gaucher's Disease 1997, vol 10:4: pp 711-723.

4 Stone DL, Van Digglen OP, De Klerk JBC et al: Is the perinatal lethal form of Gaucher disease more common than classic Type 2 Gaucher disease? Eur J Human Genet 1999; 7: 505-509.

5 Stone DL, Carey WF, Christodoulou J et al: Type 2 Gaucher disease: the collodion baby phenotype revisited. Arch Dis Child Fetal Neonatal Ed 2000; 82: F163-F166.

6 Stone DL, Tayebi N, Orvisky E, Stubblefield B, Madike V, Sidransky E: Glucocerebrosidase gene mutations in patients with Type 2 Gaucher disease. Hum Mutat 2000; 15: 181-188.

7 Mignot C, Gelot B, Bessières B et al: Perinatal-lethal Gaucher disease. Am J Med Genet 2003; 120A: 338-344

8 Finn LS, Zhang M, Chen SH, Scott CR: Severe Type II Gaucher disease with ichthyosis, arthrogryposis and neurological apoptosis: molecular and pathological analysis. Am J Med Genet 2000; 91: 222-226.
9 Hatton CE, Cooper A, Whitehouse C, Wraith JE: Mutation analysis in 46 British and Irish patients with Gaucher's disease. Arch Dis Child 1997; 77: 17-22.

10 Eyal N, Wilder S, Horowitz M: Prevalant and rare mutations among Gaucher patients. Gene 1990; 96: 277-283.

11 Bodamer OAF, Church HJ, Cooper A, Wraith JE, Scott CR, Scaglia F: Variant Gaucher disease characterised by dysmorphic features, absence of cardiovascular involvement, laryngospasm and compound heterozygosity for a novel mutation (D409H/C16S). Am J Med Genet 2002; 109: 328-331.

12 Dvir H, Harel M, McCarthy A et al: X-ray structure of human acid$\beta$-glucosidase, the defective enzyme in Gaucher disease. EMBO Rep 2003; 4: 704-707.

13 Grabowski GA, Horowitz M: Gaucher's disease: molecular, genetic and enzymological aspects; in Zimran A (ed): Balliere's Clinical Haematology: Gaucher's Disease 1997, vol 10:4: pp 635-656. 